\title{
EDITORIAL
}

\section{New Editor-in-Chief: reviews}

Published online: 5 April 2013

(c) Springer-Verlag Berlin Heidelberg 2013

Scientists produce knowledge, new knowledge is communicated in scientific publications, and scientific publications abound. There is need for structuring and aggregating this wealth of information so that individual scientists can keep track of advances beyond their immediate field of competence. Plant Cell Reports offers this service to its readers in the form of reviews, opinion articles and special issues that shed light on particular subjects. These are intended to provide a comprehensive overview of the state of the art, highlight significant new advances, help identify obstacles to further advances and discuss possible solutions, and give an outlook on possible developments in the field.

Organizing this reviews feature in its different facets, assuring the highest possible quality, overall and in each individual contribution, demands dedication and competence. It is our great pleasure to introduce to our readers
Neal Stewart, the new Editor-in-Chief Reviews, in charge of the reviews feature of Plant Cell Reports. Neal Stewart holds the Ivan Racheff Chair of Excellence in Plant Molecular Genetics and is a professor at the Department of Plant Sciences, University of Tennessee in Knoxville, USA.

In addition to the regular flow of reviews on topical subjects, we are looking forward to the upcoming special issue on "Plant Hormone Signaling". The call for contributions has met with great success and the high-quality contributions are currently being processed. The special issue will be available this summer.

The Editors-in-Chief, Günther Hahne Jang R. Liu 